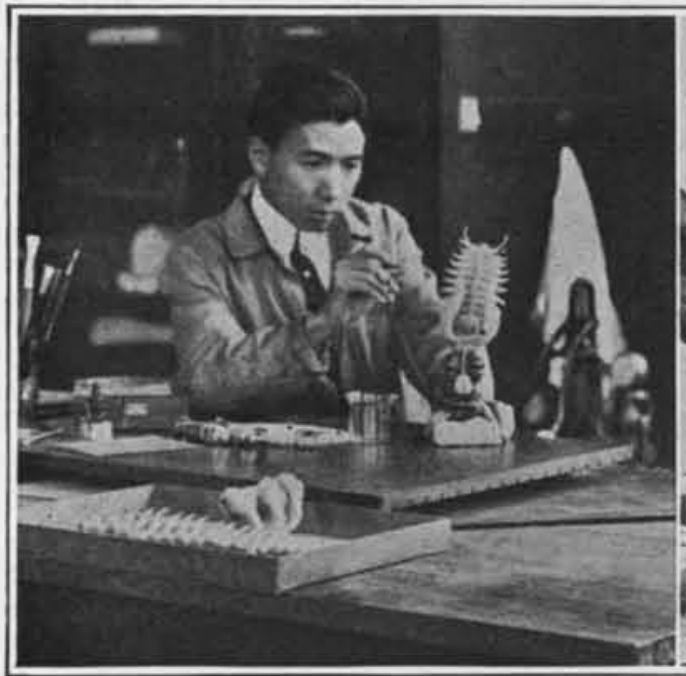

Coloring a model of an invertebrate with an air brush

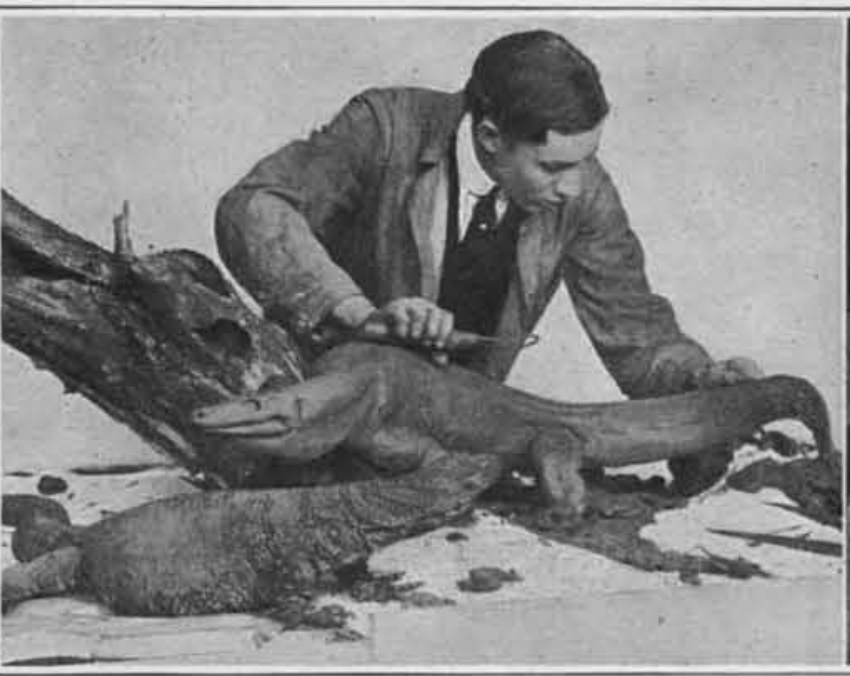
Mr. Dwight Franklin Modeling a

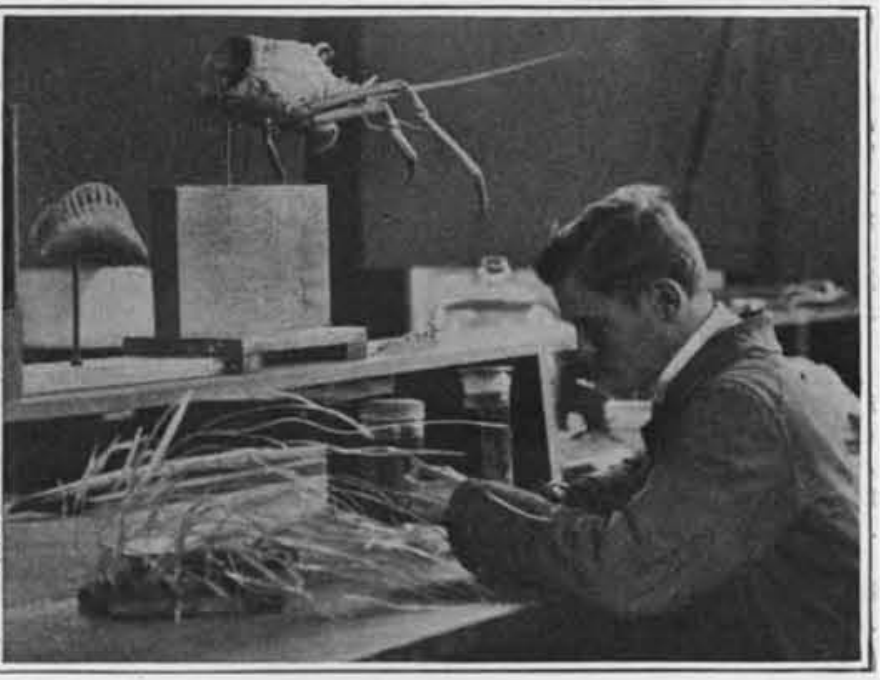

Making artificial seaweed from

\title{
Behind the Exhibits
}

\section{Departments and Activities of a Museum Which the Layman Never Sees}

\section{By Albert A. Hopkins}

$A^{S}$ we roam through the halls of a great museum we A are prone to think that the exhibits require little preparation before they are shown to the public. The very reverse is the fact, and a few astounding statements can be made which may not be true for al museums, yet are correct for the greatest of them all the American Museum of Natural History. .In the first place, about four-fifths of the material is in storage, not necessarily boxed up and piled in storerooms, but arranged in fireproof, dustless rooms, cases, presses, and other containers. The rooms seem endless; yet if a student really wants to see bird skins, aboriginal skulls, prehistoric stone implements, etc., he will find a collection so extensive that the volume is almost appalling.

For example, the ethnological collection embraces 100,000 catalogued specimens. There are 2000 human crania, 500,000 insects, 150,000 bird skins, 100,000 in vertebrates from one expedition, and so on. It migh well be asked why only twenty per cent of the objects acquired are shown. The answer is simple; for in the case of Natural History the vast majority of the specimens are in the study series, not only because they would ultimately be ruined by exposure to light, but because the display of all material would only confuse the visitor. Moreover, no museum has room to show everything, and a careful selection is made of objects of the greatest educational value. These are so dis played as to enhance their interest and attractiveness. The aims of a museum of natural history are multifold and might be defined as follows:

The purposes of a great national museum of natural history are: (1) To procure by its own explorer or by the voluntary assistance of independent naturalists the actual specimens upon which accurate knowl- edge of the animals, plants, and minerals of the earth's surface, and more especially of the national territory, is based; to preserve and arrange these collections for study by all expert naturalists, and to facilitate, directly or indirectly, the publication (in the form of catalogues or monographs) of the knowledge so obtained, with a view to its utilization, not only in the progress of science, but in the service of the State. (2) To exhibit in the best possible way for the edification of the public, at whose charges these collections are made and maintained, such specimens as are fitted for exposure in public galleries, with a view to the intelligent and willing participation of the people in the maintenance of the museum. As the museum is emphatically "for the people," special attention is given to making the exhibits attractive and interesting, as well as instructive.

While the American Museum of Natural History cannot claim to have originated the idea of displaying animals amid their natural surroundings, it was the first large museum in the country to adopt this method which it has since carried out on a large scale in the well-known "habitat" groups. In the museum were also developed the methods of preparing and mounting the skeletons of extinct animals that have resulted in such mounts as Brontosaurus and Tyrannosaurus, and the series showing the development of the horse, so that they might be something more than an assemblage of uninteresting bones.

It is with the greatest liberality that this museum gives the results of special methods of preparation to the scientific world, and while the great public, to the use of which the great structure is so largely dedicated, cannot, of course, be admitted to the laboratories and preparation rooms, yet our readers will be enabled to visit pictorially, at least, these veritable hives of scientific industry. With the permission of the Director, Dr. Lucas, and under the guidance of Mr. Miner, Associate Curator of lower invertebrates, the writer spent a most fascinating day in the huge building, which is, by the bye, 710 feet long.

In the basement is located some of the shops which require considerable space, as the carpenter shop, where cases of all kinds are made as well as the wonderful queer-shaped pieces of wood for the "insides" of animals, called "armatures." The Museum staff have designed cases and moth-proof containers of all kinds which show preat inventive skill. In the Museum of the old school, and there are many of these, the objects were exhibited in a cold, formal way, out of contact with the real environment, and the skin was painfully stitched to gunny sacking covering the skeleton. The skin was distended by the judicious use of sawdust. Now all is different. A field staff goes to Africa. They are extremely versatile, some study the jungle; some study the rocks; others photograph or make color studies; while still others spend their time in investigating the habits of the huge animal who is unknowingly facing the bullet from the elephant-gun of the naturalist-hunter.

The skin and bones are preserved and are shipped home. A year or so later the staff members reassemble and begin to visualize what they have seen in far-away Africa. They build an artificial jungle of wire, wax, celluloid, glass, and the thousand and one articles which these up-to-date "preparators" consume, for the oldtime taxidermist is in the discard. The artist paints the background; the sculptor models in clay the great

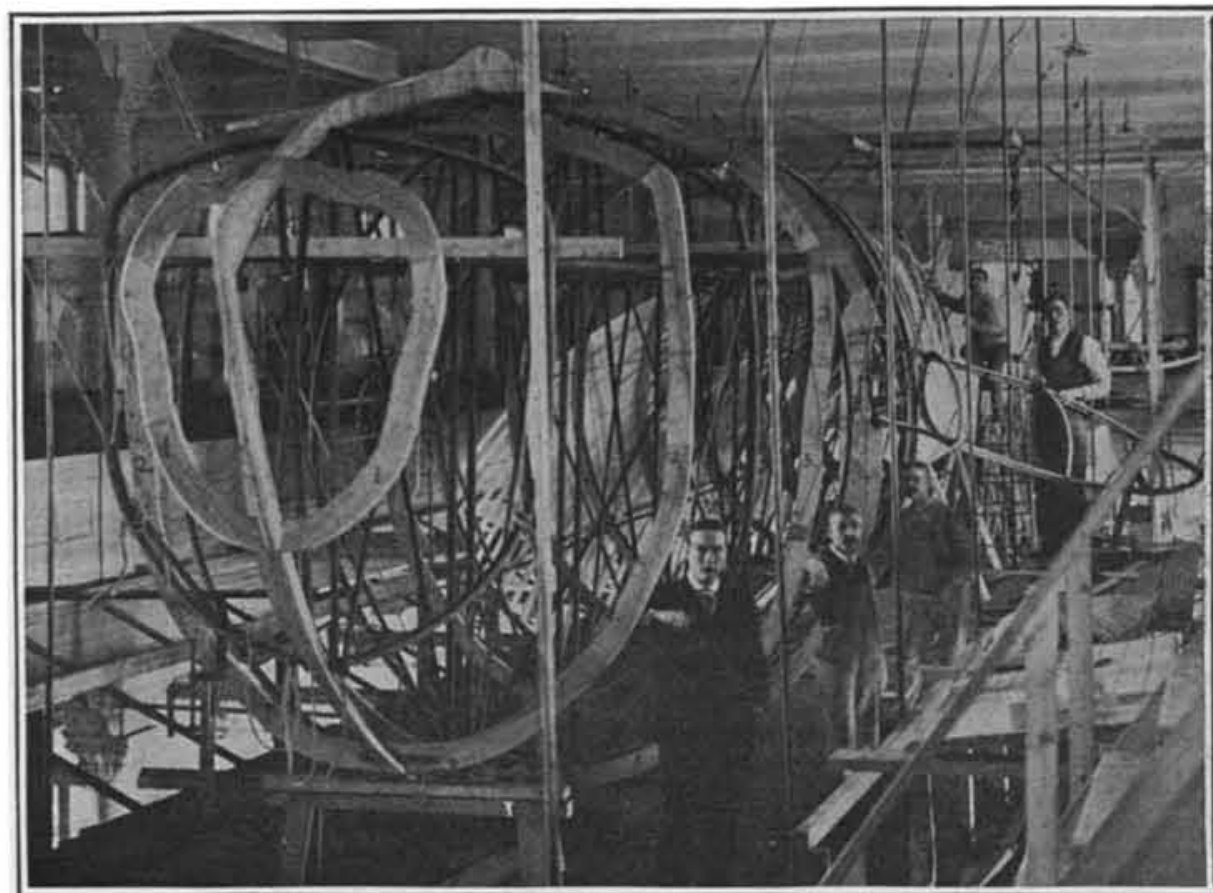

Making the framework for a whale

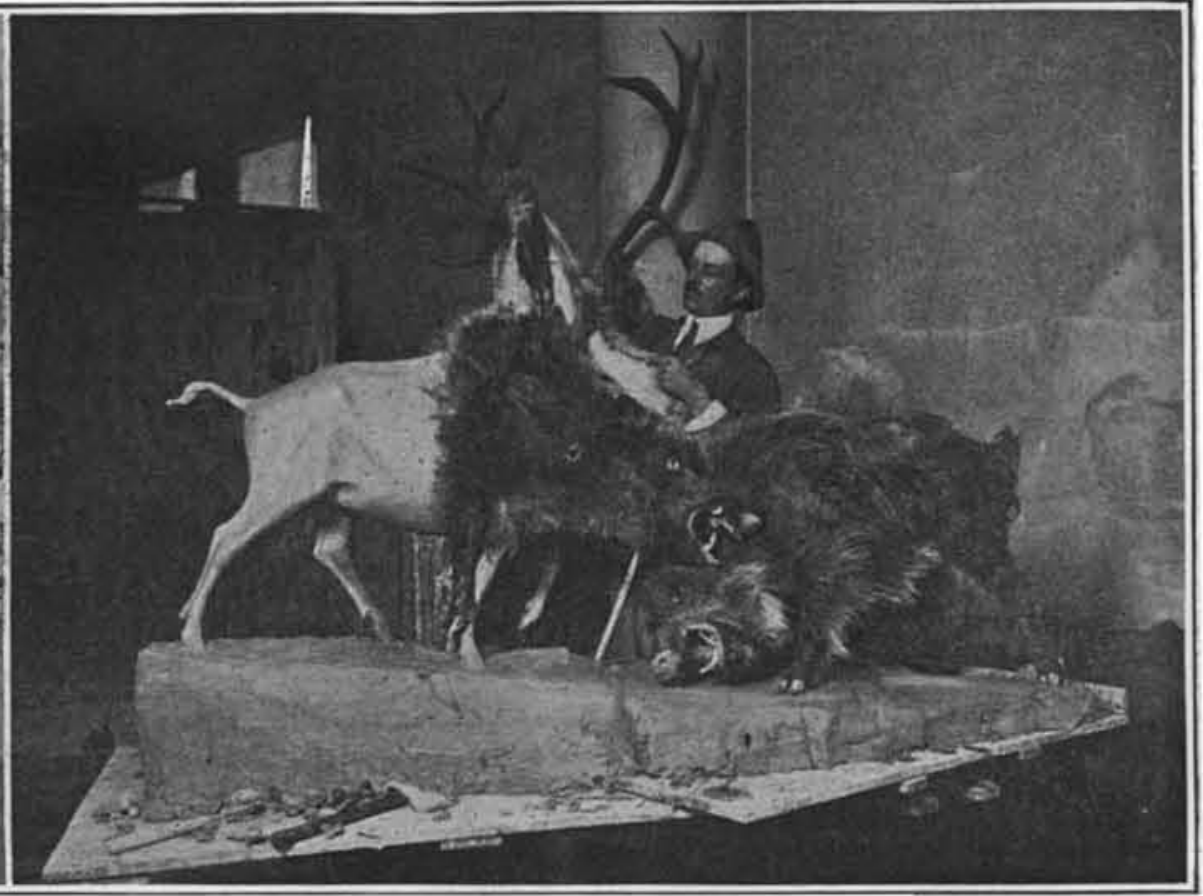

Trying on a skin over a modeled body 
bulk of the figure; plas ter casts are made, using an artificial frame work of wood and iron to take the place of the bones which are being boiled clean in an adjoining laboratory be fore they are articulated. Then comes the "trying-on" process in which the hide is fitte to the new body, and, finally comes the glass blower who takes proper notes for the eyes. In due course the public is admitted to see the completed product. Labeling comes later, Labeling comes, for a museum's label cannot be made hurriedly. The time and care lavished on labels are almost beyond belief; a set of labels often takes two years in the takes two years in the preparation. With

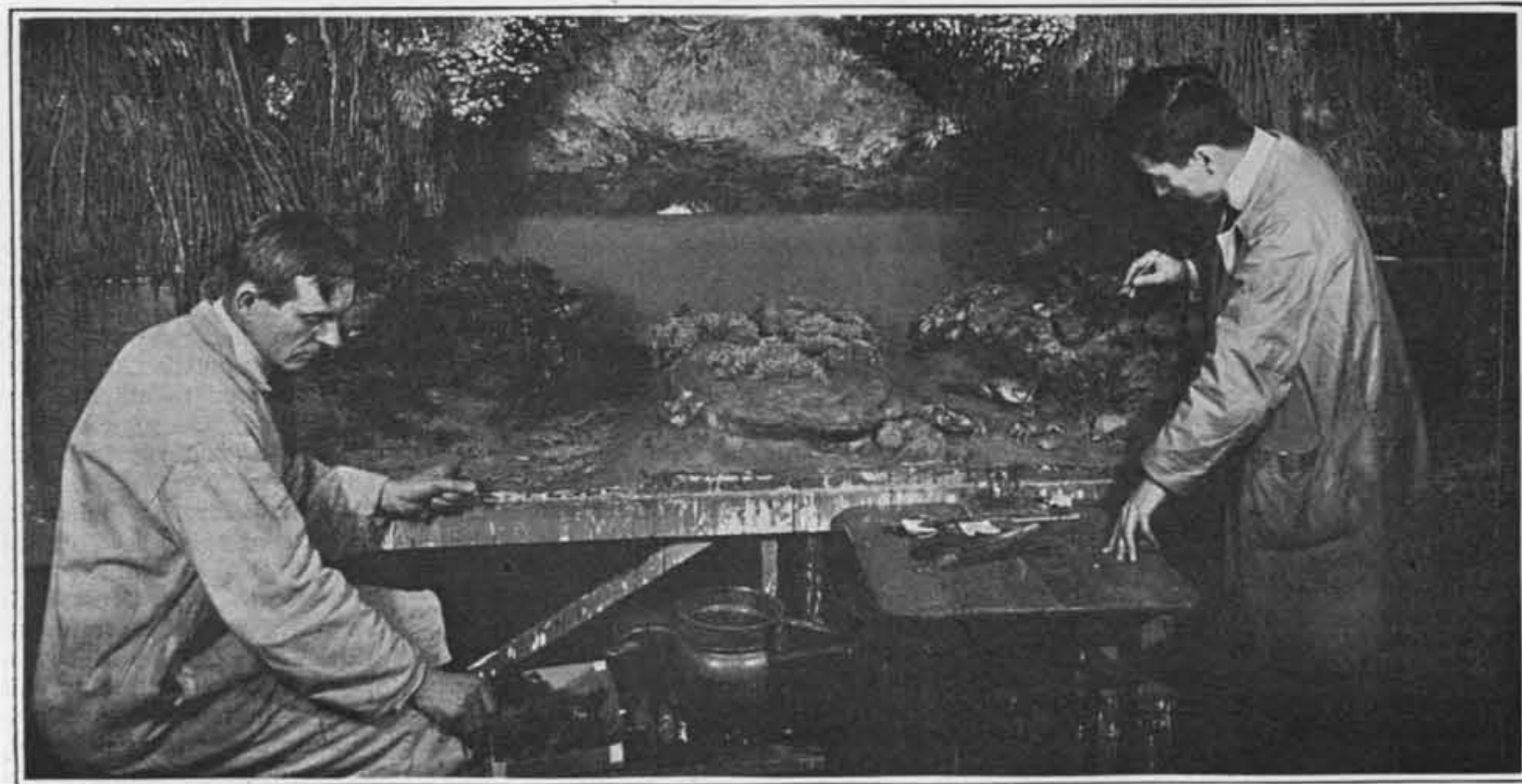

Working on the Nahant tide pool group, one of the finest marine groups ever attempted fish was also dried and with a wax foundation, the tube feet being modeled in glass and inserted. The tubularian hydroids were all separately blown in glass and welded together in colonies, the sketches made in the field and the original alcoholic specimens being used as patterns. The color was sprayed on with the air brush, the finishing touches being made by hand in the usual manner with paints. Hun dreds of tentacles for the sea anemones, cirri for the serpulid $\mathrm{Hy}$ droides dianthus; and even some of the seaweed are also the work of the glass blower, but perhaps the best work in this line is the modeling of the jellyfish method of procedure is the same, and the wonderfu bird groups have been the delight of thousands. The same general plan is adopted throughout the other fields of endeavor, such as ethnology, anthropology, geology, palaeontology, and mineralogy.

In the palaeontological portion of the geological field the specimens begin to be prepared in the locality where the find occurs. The fossils are covered with plaster of paris and gunny sacking, together with a sufficien quantity of the gang-rock to insure the great or less inbones are carefully removed from the matrix and huge flexible drill, like a gigantic dental engine, serves to fit the various bones together. The gaps are finally filled in and the huge articulated extinct animal stand out in three dimensions, or flat against a slab. Progress photographs are constantly being taken so that an imperishable record is made of the way it was all done

Wax flowers enter into nearly all of the groups, and it was found necessary to invent a whole new process, which will form the subject of a subsequent article Sometimes tin flowers are required, and the museum has to have a tinsmith who can make anything. The glass blower is an important artisan, we might almost say artist; his services are constantly required, espe cially for making models of insects, invertebrates, etc cially for making models of insects, invertebrates, etc.,
and he is all-essential when marine groups are being

This brings us to, perhaps, the most interesting phase of this fascinating subject-the invertebrate groups, which are gradually spreading from window to window in Darwin Hall. This series portrays the invertebrates in their natural surroundings, and serve to emphasize certain biological principles whch cannot to emphasize certain biological principles whch cannot groups illustrate within themselves'all those laws which lie at the basis of the doctrine of evolution, to the presentation of which Darwin Hall is dedicated. The making of these groups requires years of time. Hundreds of studies may be made in the field, from the objects themselves often drawn from observation under water, or under the microscope. These studies are by various hands and are allowed to accumulate for four or five years when the actual work of preparation i begun. The general physical presentation is discussed and small models like those designed by stage directors are made. After all ideas have been carefull aut, each one begins the fabrication of his part. One man takes crabs, for instance, removes the body from the shell; models a new body; puts it back in the shell; articulates legs and claws and paintsfor all time-the colors which were all too-evanescent in its brief life on the sandy bottom. Then there is a whelk, a hermit crab, and a snail; all are treated in sheet celluloid colored by hand and with the airbrush. Meantime the artist has been painting the background on successive sheets of glass which are constantly be ing tested for the effect. The making of seaweed is a large order; but with punches of a half dozen different designs this part of the work goes quickly enough. The specimens are studied in siter and photographs and drawings brought down from Wood's Hole, or elsewhere, and the next operation is to fix them permanently in wax or glass; for organic matter will decompose quickly, or if preserved in alcohol becomes so deformed and bleached that it is a travesty of the livin animal. The animal life, with the exception of hard structures, such as shells, is an assemblage of models.

The mussels on the piles are the actual specimen which were preserved in alcohol and afterward take apart, the soft portions cleaned out and the shell reassembled with wax and cotton. The worm tube are the natural dried specimens recolored. The starthe same way. There is eel grass to be cut out of and the squid. The former is entirely of glass and is a masterpiece of the glassblower's art, while the peculiar translucency of the squid's body could be obtained by no other medium. The coloring of these two models by the Japanese artist is also a triumph of skill. Much of the animal life, however, was modeled in such materials as wax and celluloid. A single ex hibit may consist of 200,000 to 300,000 objects fashioned by the hand of man so that it is little wonder that three or four years is a little period when a group like this is considered. The expense which runs up into thousands is fully justified on account of the permanency of the exhibit which, with proper care, will be in existence long after our grandchildren have passed away. The bryozoa group is most popular, for we apparently look through a huge magnifying glass three feet in diameter, at a bit of the bottom of the sea where the seaweed is three feet high. Alice in Wonderland never saw such a queer assemblage of wax, glass and other objects; for everything is laid under contribution, and the effect is the same as if actually viewed with a magnifying glass of normal size. Another magnifying glass will show us pond life in year or so as it is now in process of construction. We have dwelt particularly on the invertebrate groups, because of the invention which has been displayed by all these "habitat" groups, but particularly those deal ing with the lower form of animal life; for though a bird or animal group may require painstaking labor and the skill of the sculptor they do not require as much invention and resourcefulness as do the lower invertebrate groups.

It might well be asked if the time and money which are expended are justified. It is, indeed, a wise expenditure of money for the creation of educational exhibits which will prove a delight to the people for a century or more to come.

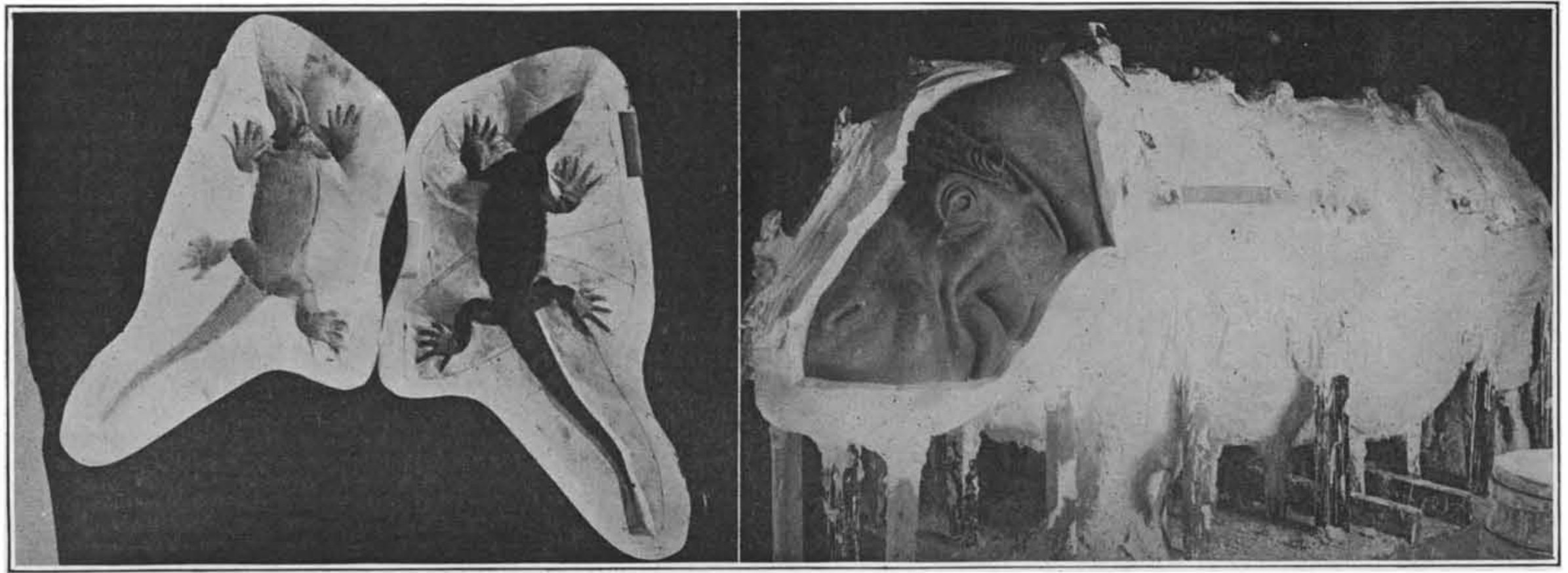

Plaster mold for casting wax lizard

Making a clay mold for a model of a hippopotamus 